\title{
Hydro Power Plants in the Interconnected Power System of Siberia: Trends and Problems
}

\author{
V.M.Nikitin ${ }^{1}$, E.N.Malinovskaya ${ }^{2}$ \\ ${ }^{1}$ D.Sc., Head of the Laboratory of Hydropower and Water Management Systems, Melentiev Energy Systems Institute, Siberian \\ Branch of the Russian Academy of Sciences \\ ${ }^{2}$ post-graduate student at Melentiev Energy Systems Institute, Siberian Branch of the Russian Academy of Sciences
}

\begin{abstract}
The paper discusses the trends, features, and current problems of the operation of hydro power plants in the interconnected power system (IPS) of Siberia. The main feature of the IPS of Siberia is a high proportion of hydro power plants and, as a result, a strong dependence of power generation on the natural fluctuations of water inflows into reservoirs. The problems affecting the power system efficiency arise when the inflows deviate from normal and close-to-normal values. The study indicates the need to improve the current system of managing and planning the operation of hydro power plants. The important factor that can increase the efficiency and reliability of the power system operation is bringing the permissible ranges of variations in reservoir levels in compliance with the design values. Planning the long-term power balances and increasing their validity should involve predictive scenarios of water inflows into reservoirs.
\end{abstract}

\section{Introduction}

In 2019, 60 years had passed since the establishment of the interconnected power system (IPS) of Siberia. Currently, it is one of the seven interconnected power systems of Russia. The main feature distinguishing it from other IPSs is a high proportion of hydro power plants (HPPs). In the IPS of Siberia, there are 112 power plants with a total capacity of $52.1 \mathrm{GW}$, including the AngaraYenisei HPP cascade (one of the largest cascades in the world) with a total installed capacity of $24.7 \mathrm{GW}$ [1]. Hydro power plants (given the Novosibirsk and Mamakan HPPs) generate about $50 \%$ of the total electricity produced in the IPS of Siberia, of which $80 \%$ is from the Irkutsk power system (the share of HPPs in the Russian Federation accounts for 18\%). The Angara HPP cascade (Fig.1) plays an essential role in the operation of the IPS of Siberia. This system includes unique multi-year Irkutsk (Lake Baikal) and Bratsk reservoirs (with a total live capacity of $96 \mathrm{~km} 3$ ), which allows storage of up to 10 $12 \%$ of the entire annual demand for electricity of the IPS. Together with the Ust-Ilimsk and Boguchany HPPs, the Angara cascade produces about $30 \%$ of the total electric power of the IPS of Siberia. At the same time, the Bratsk HPP performs the compensating function in the power system, being the regulator of the annual power balances, whereas the Bratsk reservoir provides a balanced water management system of the Angara and Yenisei basins.
The Angara and Yenisei hydro power cascades fulfill several other system-wide functions. For example, they cover the variable part of the load curve, including daily and weekly regulation, regulate frequency, and provide the major part of the load and emergency power reserves $[2,3]$.

\section{Trends}

In 1959, when the IPS of Siberia was put into operation, the share of HPPs in the structure of its capacity was less than $16 \%$. By this time, the Novosibirsk (1958) and Irkutsk (1959) HPPs with a total capacity of about $1 \mathrm{GW}$ had been commissioned. The largest hydro power plants in Siberia were mainly constructed in the 1960s-80s. These were the Bratsk HPP (1967), Krasnoyarsk HPP (1971), Ust-Ilimsk HPP (1980), and the SayanoShushenskaya and Mainskaya HPPs (1985). By the mid1980s, the total capacity of the Siberian HPPs had amounted to $22.3 \mathrm{GW}$ or $52 \%$ of the total capacity of the IPS of Siberia [2] (Fig. 1).

The construction of hydro power plants became an important regional factor determining the accelerated development of the Siberian economy. That period saw the creation of large territorial production facilities, including the most electricity-intensive industries (aluminum plants, pulp and paper mills, etc.) that used the cheapest electricity in the Soviet Union. 
Two different periods can be distinguished in the development and formation of the power system of Siberia. These periods coincide with the Soviet and postSoviet stages of political and socio-economic development of the country. The Soviet period (19601990) was characterized by a sharp increase in electricity production and consumption. Electricity consumption increased by 6 times (about 20\% per year), the total capacity of power plants - by 7 times, including that of hydro power plants - by 22 times, and thermal power plants (TPP) - by 3.9 times (Table 1).

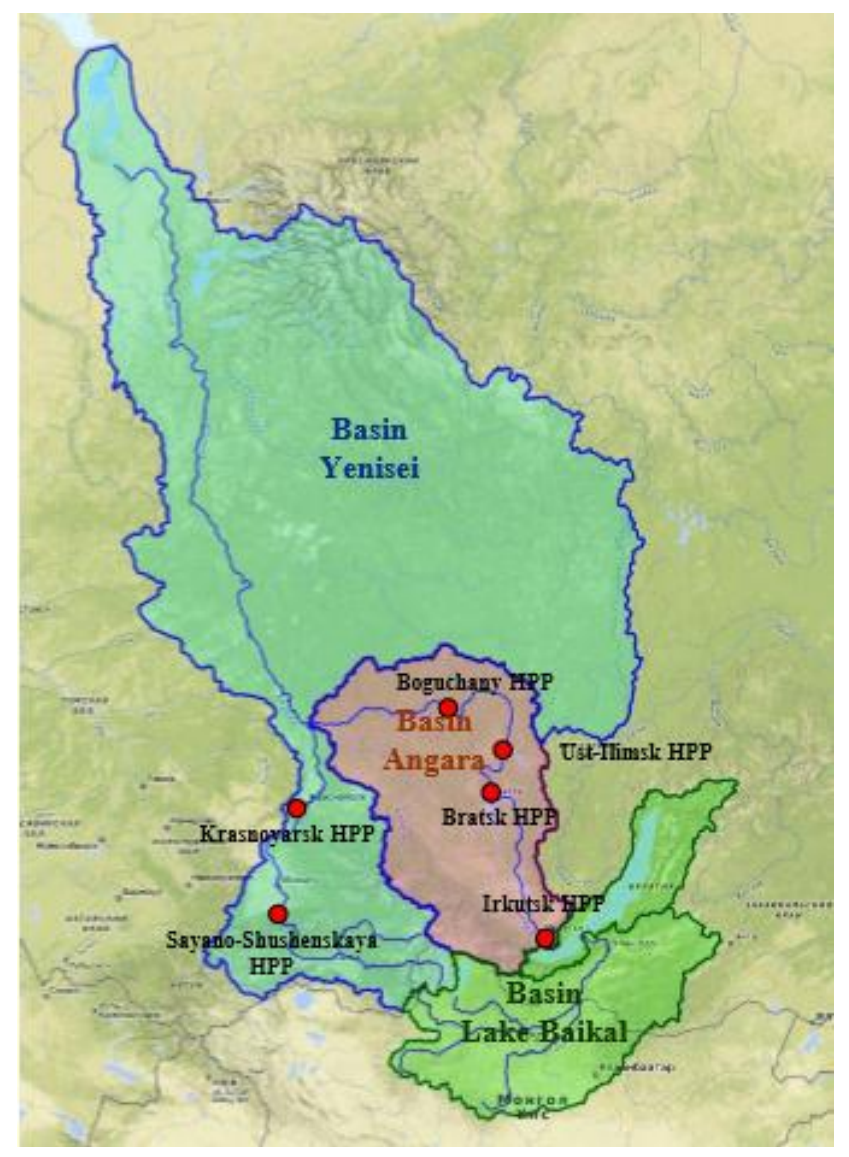

Fig. 1. The scheme of the Angara-Yenisei HPP cascade

The extremely low-water period of 1976-1982 showed a strong dependence of the IPS of Siberia on natural factors and, above all, on water inflows into the reservoirs of Siberian hydro power plants. This dependence was seen in the inability of hydro power plants to balance electricity generation and consumption in the power system in the dry period. For this reason, to improve the balance and reliability of the power system, in the second half of the 1980s, the country built several large heat generation facilities (three units of the Novosibirsk CHP5, the first unit of the Berezovskaya GRES (condensing power plant), and several $500 \mathrm{kV}$ transmission lines.

Such dynamics made it possible to balance the growth of electricity production and consumption in the power system. However, in some years, the uneven placement into the operation of units at HPPs and TPPs; commissioning of electrical networks and substations; and the emergence of energy-intensive consumers were accompanied by either shortage or surplus of electricity and power. Nevertheless, the modern structure of the IPS of Siberia was mostly shaped in the Soviet period.

There was a significant decline in electricity consumption due to the collapse of the USSR and the economic crisis from 1990 to the mid-2000s. During that period, the IPS of Siberia operated in isolation from the UPS of Russia. At the end of the 1990s, electricity consumption in the IPS of Siberia went down to $170 \mathrm{TWh}$ (dropped approximately by $20 \%$ to the 1980 level), and only in recent years, it has returned to the 1990 level. Over those years, only one hydroelectric power plant, the Boguchany HPP, with a capacity of $3 \mathrm{GW}$ was built (the construction was completed in 2015, 40 years after it started), and several new heat-generating plants and units at the existing plants with a total capacity of $6 \mathrm{GW}$ were commissioned. Also, 28 new substations and about 5 thousand $\mathrm{km}$ of 500 and $220 \mathrm{kV}$ overhead lines were put into operation [1]. The IPS of Siberia generated surplus capacity and, in some years, at the time of maximum load, the surplus was as high as $10 \mathrm{GW}$ [4]. Over the past 15 years, the IPS of Siberia has been operating under the conditions of stable power consumption and still has available power surplus (power consumption has increased by an average of only $0.1 \%$ per year).

Table 1. The structure of the capacities in the IPS of Siberia in 1960-2020

\begin{tabular}{|c|c|c|c|c|c|c|c|}
\hline Index & 1960 & 1970 & 1980 & 1990 & 2000 & 2010 & $\begin{array}{c}2020 \\
(2019) \\
\end{array}$ \\
\hline Electricity consumption TWh & 34.6 & 101.6 & 167.7 & 205.6 & 172.5 & 202.7 & 211.4 \\
\hline Total installed capacity, GW, including: & 6.3 & 22.7 & 35.1 & 43.0 & 45.5 & 47.3 & 52.1 \\
\hline HPPs & 1.0 & 10.2 & 18.7 & 22.3 & 22.3 & 22.3 & 25.3 \\
\hline TPPs (CHP +CPP + others $)$ & 5.3 & 12.5 & 16.4 & 20.7 & 23.2 & 25.0 & 26.8 \\
\hline Capacity structure, $\%$, including: & 100 & 100 & 100 & 100 & 100 & 100 & 100 \\
\hline HPPs & 15.9 & 44.9 & 53.3 & 51.9 & 49.0 & 47.1 & 48.6 \\
\hline TPPs (CHP +CPP + others $)$ & 84.1 & 55.1 & 46.7 & 48.1 & 51.0 & 52.9 & 51.4 \\
\hline
\end{tabular}

Since the early 1990s, the country's economic system has radically changed. Most of the unified state property has become private and corporate. Generating companies, grid companies, and large energy-intensive electricity consumers have become joint-stock companies. The electric power industry has been restructured and a 
wholesale market for electricity and capacity has been created. Each joint-stock company has set its objectives, strategy, and performance criteria. As a consequence, it is difficult to make long-term planning and forecasting of power demand in the power system. The construction and commissioning of new large electricity consumers are determined, first of all, by the conditions of the Russian and World markets. A good example is a delay in the construction and commissioning of the Boguchany and Taishet aluminum plants with a total design capacity of 2640 MW planned to be launched 10 years ago, before the commissioning of the Boguchany hydro power plant. The implementation of these plans, due to the unfavorable situation in the world aluminum market, remains in question for an indefinite period. There are no other large new electricity consumers in the power system so far.

\section{Specific features and problems}

The main specific feature of a power system with a high proportion of HPPs is a strong dependence of power generation on a natural factor, i.e., the natural fluctuation in water inflows into reservoirs. The deviation of the power output of hydro power plants of the Angara-Yenisei cascade from the long-term average values can be as high as $30 \%$ or 31-36 billion $\mathrm{kWh}$ per year (Table 2 ).

Table 2. Fluctuations in annual electricity generation from HPPs of the IPS of Siberia

\begin{tabular}{|l|c|c|c|c|}
\hline \multirow{2}{*}{ HPP } & Installed capacity, & \multicolumn{3}{c|}{ Annual electricity output, bn kWh } \\
\cline { 3 - 5 } & MW & Maximum & Long-term average & Minimum \\
\hline Irkutsk & 662 & 5.16 & 4.13 & 2.86 \\
\hline Bratsk & 4500 & 28.10 & 22.50 & 14.36 \\
\hline Ust-Ilimsk & 3840 & 27.17 & 21.20 & 14.34 \\
\hline Boguchany & 2997 & $22.90^{*}$ & $17.60^{*}$ & $11.40^{*}$ \\
\hline Angara Cascade ** & 11999 & 83.33 & 65.43 & 42.96 \\
\hline Sayano-Shushenskaya & 6400 & 30.70 & 23.65 & 16.45 \\
\hline Mainskaya & 321 & 2.00 & 1.71 & 1.35 \\
\hline Krasnoyarsk & 6000 & 25.90 & 19.90 & 13.67 \\
\hline Yenisei cascade ** & 12721 & 58.60 & 45.26 & 31.47 \\
\hline Angara-Yenisei cascade** & 24720 & 141.93 & 110.89 & 74.43 \\
\hline Novosibirsk & 455 & 2.41 & 1.99 & 1.57 \\
\hline Mamakan & 100 & 0.17 & 0.16 & 0.15 \\
\hline IPS of Siberia, total ${ }^{* *}$ & 25268 & 144.51 & 112.84 & 76.15 \\
\hline
\end{tabular}

Note: $*$ - calculated values.

** - the aggregate indices for the HPP cascades and the entire IPS of Siberia did not take into account the asynchronous runoff in different river basins and individual reservoirs within one basin.

Problems in the IPS of Siberia and related water management and socio-economic systems arise when inflows deviate from normal and close-to-normal values. In low-water (extremely dry) periods, the electricity production at hydro power plants is significantly reduced, the power balance in some areas of the IPS of Siberia is disturbed, and hydropower reserves in the long-term storage reservoirs decline. In general, the overall reliability and stability of both the power system and the water management system are reduced.

Throughout the whole period of the Angara HPP cascade operation, there were two such periods: 1976-1982 and 2014-2017. The extremely dry years (1976-1982) coincided with reduced electricity production at thermal power plants in the IPS of Siberia, which was due to fuel undersupply and related electricity shortage in the system by the end of the low-water period. By 1979, to compensate for the decrease in electricity production at TPPs, longterm water reserves in the Irkutsk (Lake Baikal) and Bratsk reservoirs had been completely depleted. As a result, along with the failure of power supply to consumers, the requirements of other water users and water consumers were not fulfilled either [2]. The 2014-2017 years, which were even severer in terms of inflow volume, caused less damage: navigation period was shortened, long-term resources of the Bratsk reservoir were almost completely drawn down, electricity production at the Angara HPP cascade decreased by $15-20 \%$. The insufficient electricity production from the HPPs during that period was compensated by the electricity generation from thermal power plants. The reason is the available sufficient reserves and surplus capacity in the power system, and the capability to maintain the maximum possible saving of water resources [5].

Problems arise in high-water years as well. Due to the limited need of the power system for electricity during flood periods (that usually occur in summer), as well as the insufficient transfer capability of intersystem and intrasystem power lines, there are risks of overflowing reservoirs and idle discharges through the throughput facilities of HPPs, and flooding of territories located in the upper and lower pools. The latter relates primarily to Lake Baikal and the lower pool of the Irkutsk HPP.

A specific feature of the power system with a high proportion of HPPs is the structure and dynamics of the intra-annual load curve. Every year from March to October 
there is a seasonal decrease in power consumption. The same period (April-October) sees the maximum inflows into the reservoirs of HPPs and, consequently, the maximum generation of electricity from HPPs (Fig. 2).

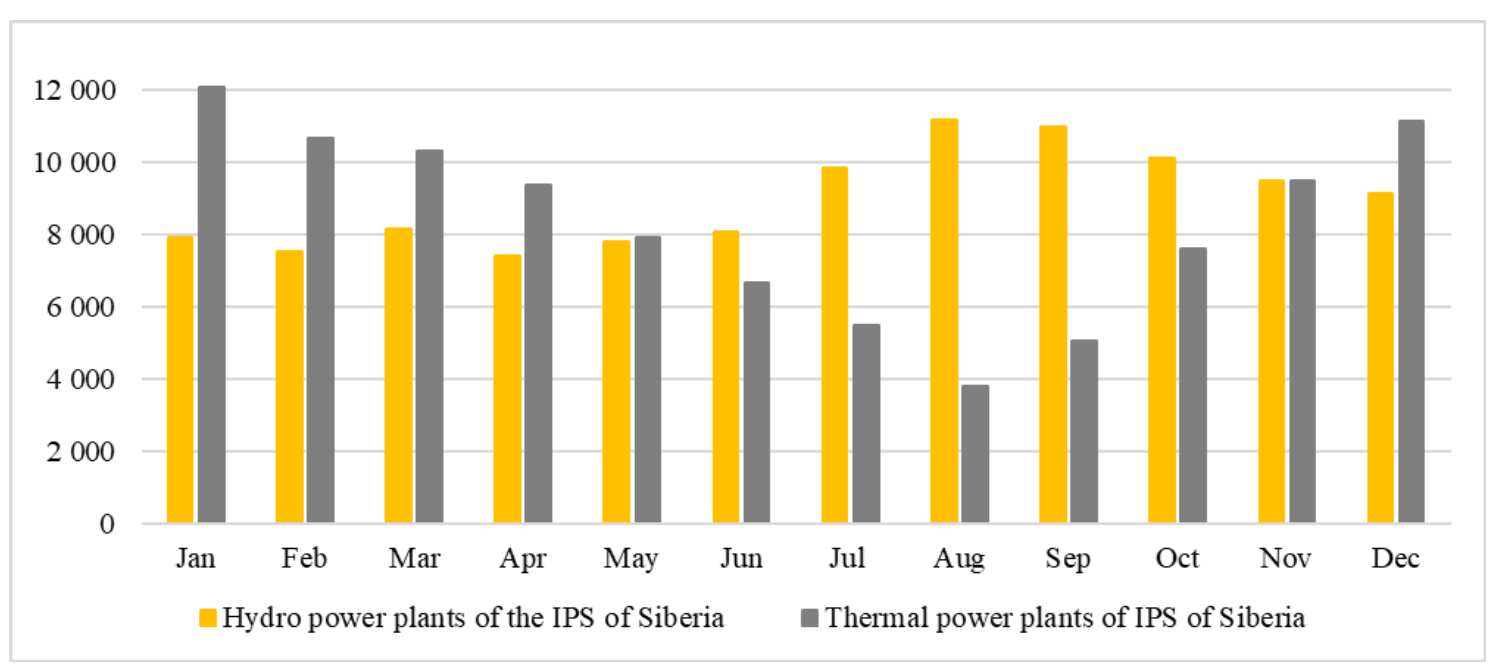

Fig. 2. Generation structure of the IPS of Siberia on the example of 2019, million kWh

Seasonal non-uniformity of electrical loads, with a limited variable part of the load curves, is compensated by unloading thermal power plants. In summer, some thermal power plants are unloaded to a minimum safe output, some are switched to heat generation only (Krasnoyarskaya GRES (CPP) 2 and CHP 1), or completely stop (Berezovskaya GRES (CPP) 1) (Fig. 3). This situation is repeated annually even in the average-water years, including 2019 (Fig. 4). In wet years, the HPP generation increases significantly. In this case, thermal power plants (including those the most efficient of them) are forced to unload (some of them are unloaded even below the minimum safe output), which complicates planned maintenance of energy equipment and electrical networks, carried out mainly in summer. As a result, the overall economic efficiency and reliability of the power system are reduced.

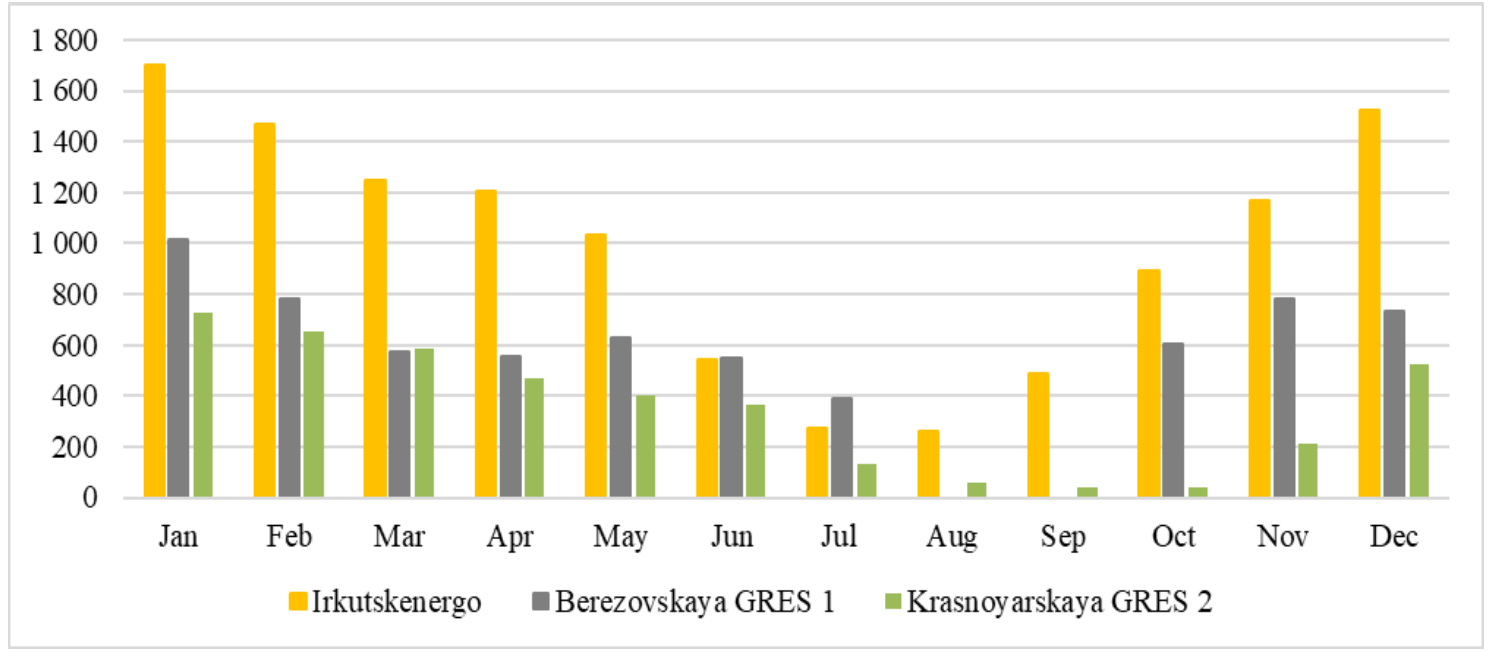

Fig. 3. Generation structure of the largest thermal power plants of the IPS of Siberia on the example of 2019, million kWh

The operating conditions of hydro power plants are also affected by intra-seasonal water management and environmental requirements, as well as daily regulation restrictions. In the summer-autumn period, these entail the requirements for navigation flows through HPPs and fishery restrictions during spawning periods. A significant limitation for the lower pools of the Krasnoyarsk HPP and, especially, the Irkutsk HPP, is the one on the flows through the HPPs aimed at preventing flooding of adjacent territories. In winter, there are restrictions on the maximum flow in the lower pools associated with ice conditions. 


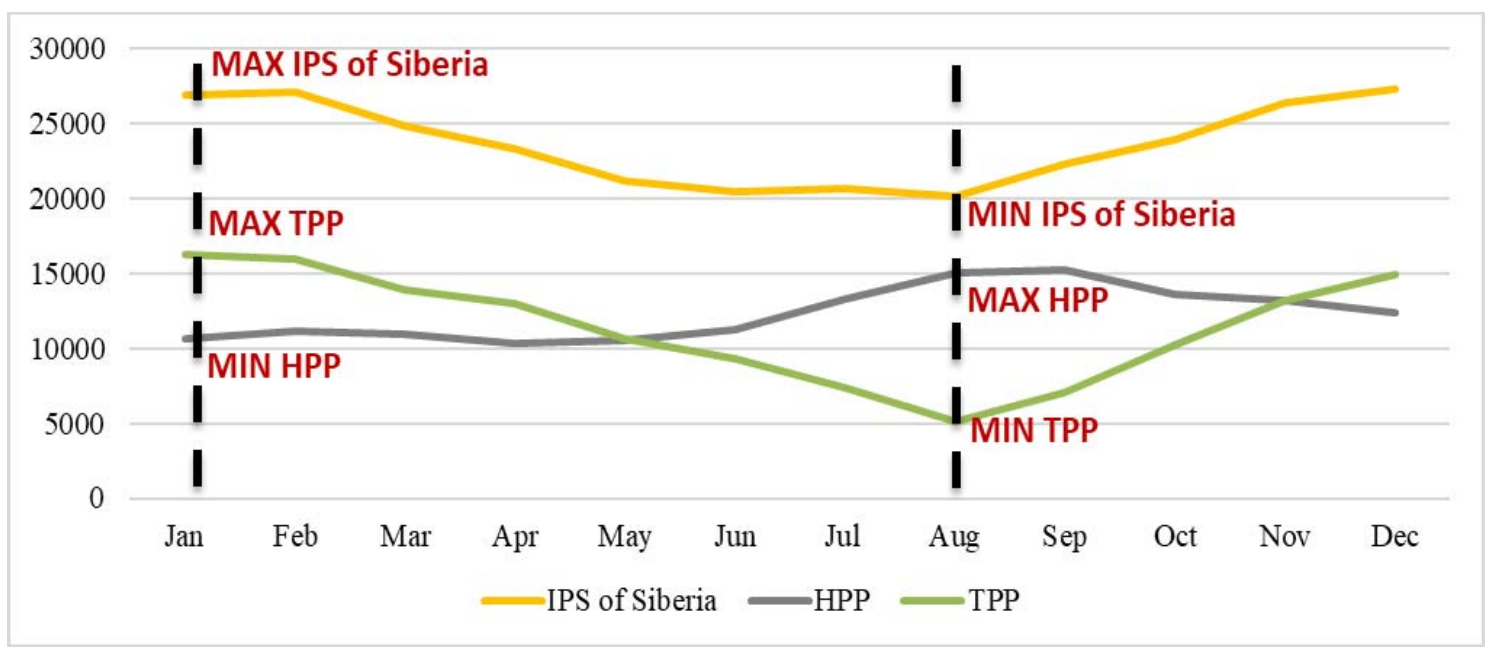

Fig. 4. The structure of the maximum and minimum generation in the IPS of Siberia on the example of 2019, MW

There is a problem related to the limitation of the transfer capability of intra-system and intersystem electrical networks. The IPS of Siberia is generally selfsufficient in terms of the electricity generation and consumption balance (power flow from other IPSs is about $1 \%$ of the total consumption). However, there are both power-surplus and power-deficient areas in the IPS of
Siberia, which is due to the limited network transfer capabilities in critical cutsets.

An important factor that affects the operation of HPPs in the IPS of Siberia is the deviation of the permissible reservoir levels and flows through the hydraulic structures from design values, which is especially true for the HPPs and reservoirs of the Angara cascade, whose design characteristics are presented in Table 3.

Table 3. Design characteristics of the Angara HPP cascade

\begin{tabular}{|c|c|c|c|c|c|}
\hline Characteristics & Irkutsk HPP & Bratsk HPP & Ust-Ilimsk HPP & $\begin{array}{l}\text { Boguchany } \\
\text { HPP }\end{array}$ & $\begin{array}{l}\text { Angara } \\
\text { cascade }\end{array}$ \\
\hline \multicolumn{6}{|c|}{ Hydro power plant parameters: } \\
\hline Commissioning year & 1959 & 1967 & 1980 & 2015 & \\
\hline Installed capacity MW & 662.4 & 4500 & 3840 & 2997 & 11999.4 \\
\hline $\begin{array}{l}\text { Average long-term electricity } \\
\text { generation, billion } \mathrm{kWh} / \text { year }\end{array}$ & 4.1 & 22.5 & 21.2 & 17.6 & 5.4 \\
\hline $\begin{array}{l}\text { Average long-term water inflow into } \\
\text { the reservoir, } \mathrm{km}^{3}\end{array}$ & 59.5 & 91.1 & 99.3 & 105.3 & \\
\hline Design head, $\mathrm{m}$ & 26 & 101.5 & 85.5 & 70 & \\
\hline \multicolumn{6}{|c|}{ Reservoir parameters: } \\
\hline Normal water surface (NWS), m & 457.0 & 401.73 & 296.0 & 208.0 & \\
\hline Dead storage level (DSL), $\mathrm{m}$ & 455.54 & 391.73 & 294.5 & 207.0 & \\
\hline Maximum water surface (MWS), $\mathrm{m}$ & 458.2 & 402.5 & 296.6 & 209.5 & \\
\hline Reservoir surface area, $\mathrm{km}^{2}$ & 33000 & 5470 & 1870 & 2320 & 42660 \\
\hline Total storage capacity, $\mathrm{km}^{3}$ & 48.4 & 162.3 & 58.9 & 58.2 & 327.8 \\
\hline Live capacity, $\mathrm{km}^{3}$ & 48.4 & 48.2 & 2.8 & 2.3 & 101.7 \\
\hline
\end{tabular}

Irkutsk Hydro Power Plant (Lake Baikal). After the Resolution of the Government of the Russian Federation No. 234 of March 26, 2001 (herein referred to as the Resolution) on the necessity of compulsory fulfillment of the limited one-meter range when regulating the level of Lake Baikal (456 $\div 457 \mathrm{~m}$ Pacific system (PS)) came into force [6], the permissible range halved relative to the design one $(455.54 \div 457.50 \mathrm{~m} \mathrm{PS}$, (Table 3$)$ ). In 20152020 , due to the extremely low water period that began in 2014, this Resolution was temporarily suspended. However, it will be brought into effect again in 2021. This Resolution changed the storage conditions not only for Lake Baikal but also for the entire Angara cascade since
Lake Baikal provides more than $60 \%$ of the total inflow into the downstream reservoirs. Baikal has ceased to fulfill the functions of long-term runoff regulator, which is stipulated by the Rules for the Use of Water Resources of reservoirs (herein referred to as "RUWR") and the Technical Design of the Irkutsk HPP [7,8]. In the last 20 years, the Lake Baikal has only been providing seasonal regulation. The 2014-2017 period of extremely low water demonstrated the insufficient validity and impossibility of implementing the Resolution under the water conditions other than normal one [9].

Bratsk hydro power plant. The regulation range of the Bratsk reservoir also deviates from the design one. Even in 
the stage of the HPP construction, the benchmarks of water intakes and piers in the water area of the reservoir were set at $395 \mathrm{~m}$ PS, which is $3 \mathrm{~m}$ higher than the design dead surface level (Table 3). As a result, the ten-meter regulation range decreased to a seven-meter one.

In the Ust-Ilimsk and Boguchany reservoirs, the possibility of summer navigational drawdown to the dead storage level is also not provided for, and thus their design regulation capability is reduced.

Thus, the resources of long-term regulation of the entire Angara cascade have decreased by about half, which is equivalent to 10 billion $\mathrm{kWh}$ of annual electricity output. The principles of using long-term water resources of reservoirs are not regulated by law.

The current management and planning system can also be viewed as a problem. Energy and water management systems are closely interrelated through the operation of hydro power plants (cascades of hydro power plants). The reservoirs of the Angara-Yenisei HPP cascade are of a comprehensive and multipurpose nature. They are used not only for energy needs but also for water supply, water transport, fisheries, and other purposes. However, the operation of hydro power plants is managed and planned by different departments - the System Operator (SO) in the electric power industry and the Federal Agency of Water Resources (FAWR) in the water management systems, which use different approaches. After restructuring, the power industry switched to market conditions. Currently, there are wholesale and retail electricity and capacity markets, including a day-ahead market and a balancing market, where pricing is based on the balance between the demand of the consumer and supply of the generator, including hydro power plants [3]. At the same time, the water sector management relies on the administrative system. Water legislation on the use of water resources is currently regulated by the Water Code [10]. According to the Water Code, $100 \%$ of water bodies are in the state ownership, including $95 \%$ in the federal one. Economic management mechanisms imply payments for the use of water bodies under the water use agreements. Regulatory documents do not stipulate a management system corresponding to the conditions of a market economy that stimulates rational water use [11]. In practice, the management of hydropower resources under the Water Code and RUWR is confined to the situation where the regional division of Federal Agency of Water Resources, i.e., the Yenisei Basin Water Administration (YBWA) prescriptively sets the flows through the hydropower facilities for the coming month, taking into account the current hydrological conditions (the current state of reservoir levels and the expected inflow). At the same time, the proposals of power engineers, and other water users that are members of the advisory interregional working group at YBWA are only advisory in nature. The YBWA (FAWR) independently determines the flows (and, consequently, the electricity generation) of hydro power plants, and, hence, the operation of the IPS of Siberia.
Economic criteria, including potential risks and damages, are not considered when distributing water resources between water users. In the context of limited water resources, this inevitably leads to their inefficient use and contradiction between the water sector participants, primarily between the energy industry and water transport.

Another management and legislation problem is the administrative principle of distributing water resources between water users and water consumers in the absence of economic criteria. Since the future water inflows into the reservoirs are uncertain and the water resources are used for many purposes, the standard calculated water availability is used as the main criterion of distribution and index of the reliability of meeting the water demand. This principle is legislatively enshrined in the current Methodological Guidelines [12], which serve as a basis for RUWR development. It is worth noting that these standards of calculated water availability were developed 60 years ago [13]. Moreover, they are the same for all reservoirs in the country, without exception. In this regard, it is necessary to conduct a feasibility study on the calculated water availability for each basin with its water users, given current conditions, features, requirements, and restrictions, and to periodically update these indices in the future.

In water management systems, the reservoir operational conditions are planned for 1-3 months. The monthly planning horizon for HPP operational conditions is associated with the extreme difficulty in the long-term forecasting of water inflows into reservoirs. At present, the Hydro Meteorological Center provides a probable (interval) forecast of inflows for the coming month at the end of the previous one (before the 25 th day of month) and for three months - once a quarter. There are no forecasts for a longer period. At the same time, planning and forecasting in the electric power industry are carried out for the future up to 1 year or more, which is due to the need to build longterm planned balances of electricity and power in the power system. These balances allow planning the electricity and heat output from thermal power plants, building fuel reserves, planning repairs of power equipment and electrical networks, and solving other problems. In the absence of the forecasts on the water inflows into reservoirs for a period of more than three months, long-term forecasting and planning of power balances rely on statistics over the past period in the form of long-term and monthly averages. Such planning and forecasting give acceptable results for normal conditions (close to long-term average) but are not justified for the extremely high or low water periods. The statistics of observations of tributaries in the basins of Lake Baikal and the Angara river over the past 120 years show that the proportion of normal and close-to-normal water years is less than $50 \%$ of the total number of years. Besides, recent decades have seen significant global and regional climate changes that alter the prevailing trends, which also makes the use of long-term and monthly-average indicators for 
forecasting ineffective [14]. In this regard, it is advisable to use new approaches to building long-term power balances. For example, one can use prognostic scenarios of water inflows into reservoirs for a period of up to 1 year based on the data from global climate models and correct them monthly [15].

The discussed features and problems reduce the efficiency of using water resources in the IPS of Siberia. Taking them into account in long-term planning and solving individual problems (where it is economically and socially justified) create potential opportunities for its enhancement.

\section{Conclusion}

1. In recent years, the operation of the IPS of Siberia has been characterized by stable power consumption and surplus available power of power plants. In the coming years, the emergence of new large electricity consumers is not expected. In the medium term, the main objective of the power system expansion is not the commissioning of new generating capacities and an increase in electricity production, but rather the improvement in the reliability and efficiency of the existing energy facilities.

2. The main feature of the IPS of Siberia is a high proportion of hydro power plants and, as a result, a strong dependence of power generation on the natural fluctuations of water inflows into reservoirs. The problems affecting the power system efficiency arise when the inflows deviate from normal and close-to-normal values.

3. An important factor that can increase the efficiency and reliability of the power system operation is bringing the permissible ranges of variations in reservoir levels in compliance with the design values and introducing appropriate changes in legislation and regulatory framework. These will increase the regulation capabilities of the reservoirs and ensure the reliable operation of hydropower plants under extreme water conditions.

4. The study indicates the need to improve the current system of managing and planning the operation of hydro power plants within the interacting energy and water management systems, using the criteria of economic, social, and environmental efficiency.

5. Planning the long-term power balances and increasing their validity should involve predictive scenarios of water inflows into reservoirs for a period of up to 1 year, and their monthly adjustment.

\section{References}

[1] The system operator of the Unified Energy System DCO of Siberia. Available at: https://soups.ru/?id=odu_siberia .

[2] Savelyev V.A. Current problems and the future of Siberian hydropower. Novosibirsk: Publishing House "Nauka", 2000. 200 p. In Russian.
[3] Modern market-based electric power industry of the Russian Federation. The 3rd edition/ ed. by Barkin O.G.M .: Publishing House "Pero", 2017. 532 p. In Russian.

[4] Gvozdev D.B., Kurbatov A.P. Problems of managing hydropower plants of Siberia in a new economic environment// Electrical stations. 2004, No. 3. pp. 62 - 67. In Russian.

[5] Abasov N.V., Bolgov M.V., Nikitin V.M., Osipchuk E.N. On regulation of the level conditions of Lake Baikal // Vodnye Resursy. 2017. Vol. 44, No. 3. pp. 407 - 416. In Russian.

[6] Decree of the Government of the Russian Federation No. 234 of March 26, 2001 "On limit values of the water level in Lake Baikal during economic and other activities" Available at http://www.poiskzakona.ru/154378.html .

[7] The basic rules for the use of water resources of the reservoirs of the Angara cascade of hydroelectric power stations (Irkutsk, Bratsk, and Ust-Ilimsk). M.: Publishing House of the Ministry of Land Reclamation and Water Resources of the RSFSR, 1988.65 p.

[8] Irkutsk Hydroelectric Power Plant on the Angara river: Technical project. M.: Publishing house of the Moscow branch of the Institute "Hidroenergoproekt", $1951.80 \mathrm{p}$.

[9] Nikitin V.M., Abasov N.V., Bychkov I.V., Osipchuk E.N. The level regimes of Lake Baikal: problems and contradictions // Geography and Natural Resources. 2019, No. 4. pp. 74 - 83. In Russian.

[10] The Water Code of the Russian Federation dated 03.06.2006 No. 74-FZ- http://www.poisk-zakona.ru / $154378 /$

[11] Management of water resources of Russia. M.: AMAPRESS, 2008. 288 p. In Russian.

[12] Guidelines for the development of the rules for the use of reservoirs. Order of the Ministry of Natural Resources of the Russian Federation dated January 26, 2011 No. 17. Available at: http://www.consultant.ru/document/ cons_doc_LAW_113871/

[13] The methodology of the economic selection of the firm power of hydroelectric power plants/ A.L. Velikanov, I.P. Druzhinin, S.N. Kritsky, et al. // Problems of hydropower and river flow regulation. M.: Publishing House of the Academy of Sciences of the USSR, 1960. Issue 8. pp. 3 - 46. In Russian.

[14] Nikitin V.M., Abasov N.V., Berezhnykh T.V., Osipchuk E.N. Angara-Yenisei cascade of hydropower plants in a changing climate // Energy Policy, 2017, vol. 4, pp. 62 - 71. In Russian.

[15] Abasov N.V., Nikitin V.M., Osipchuk E.N. A system of models to study the long-term operation of hydropower plants in the Angara cascade // Energy Systems Research, Vol. 2, No 2(6), 2019. pp. 5 - 18. In Russian. 